\section{( \\ OPEN ACCESS}

\title{
UK wide survey on the prevention of post-ERCP pancreatitis
}

\author{
Mina S Hanna, ${ }^{1}$ Andrew J Portal, ${ }^{1}$ Ashwin D Dhanda, ${ }^{2}$ \\ Robert Przemioslo ${ }^{3}$
}

- Additional material is published online only. To view please visit the journal online (http://dx.doi.org/10.1136/ flgastro-2013-100323).

${ }^{1}$ Department of Gastroenterology and Hepatology, Bristol Royal Infirmary, University Hospitals Bristol NHS Trust, Bristol, UK ${ }^{2}$ School of Clinical Sciences, University of Bristol, Bristol, UK ${ }^{3}$ Department of Gastroenterology, Frenchay Hospital, North Bristol NHS Trust, Bristol, UK

\section{Correspondence to}

Dr Mina S Hanna, Department of Gastroenterology and Hepatology, Bristol Royal Infirmary, Upper Maudlin Street, Bristol BS2 8HW, UK Mina.Hanna@nhs.net

Received 5 March 2013 Revised 8 August 2013 Accepted 14 August 2013 Published Online First 3 September 2013
To cite: Hanna MS,

Portal AJ, Dhanda AD, et al. Frontline Gastroenterology 2014;5:103-110.
ABSTRACT

Objective In 2010, the European Society of Gastrointestinal Endoscopy delivered guidelines on the prophylaxis of postendoscopic retrograde cholangiopancreatography (post-ERCP) pancreatitis (PEP). These included Grade A recommendations advising the use of prophylactic pancreatic stent (PPS) and nonsteroidal anti-inflammatory drugs (NSAIDs) in high-risk cases. Our study aim was to capture the current practice of UK biliary endoscopists in the prevention of PEP.

Design In summer 2012, an anonymous online 15-item survey was emailed to 373 UK consultant gastroenterologists, gastrointestinal surgeons and radiologists identified to perform ERCP

Results The response rate was 59.5\% (222/373). Of the respondents, $52.5 \%$ considered ever using PPS for the prevention of PEP. PPS users always attempted insertion for the following procedural risk factors: pancreatic sphincterotomy (48.9\%), suspected sphincter of Oddi dysfunction (46.5\%), pancreatic duct instrumentation (35.9\%), previous PEP $(25.2 \%)$, precut sphincterotomy (8.5\%) and pancreatic duct injection (7.8\%). Prophylactic NSAID use was significantly associated with attempts at PPS placement $(p<0.001) .64 .1 \%$ of non-PPS users cited a lack of conviction in their benefit as the main reason for their decision. Self-reported pharmacological use rates for PEP prevention were: NSAIDS (34.6\%), antibiotics $(20.6 \%)$, rapid intravenous fluids (13.2\%) and octreotide (1.6\%). $6 \%$ routinely measured amylase post-ERCP.

Conclusions Despite strong evidence-based guidelines for prevention of PEP, less than $53 \%$ of ERCP practitioners use pancreatic stenting or NSAIDs. This suggests a need for the development of British Society of Gastroenterology guidelines to increase awareness in the UK. Even among stent users, PPS are being underused for most high-risk cases. Prophylactic pharmacological measures were rarely used as was routine post-ERCP serum amylase measurement.

\section{BACKGROUND}

Postendoscopic retrograde cholangiopancreatography (post-ERCP) pancreatitis (PEP) is the most common and serious complication of ERCP. In a systematic review of 16855 unselected patients undergoing ERCP, the incidence of PEP was approximately $3.5 \%$. While its severity is most commonly mild or moderate, approximately $11 \%$ of cases are severe. The overall PEP mortality rate was 3.1\%. ${ }^{1}$

Numerous patient-related and procedure-related risk factors for the development of PEP have been identified. $^{2-4}$ Much effort has been made to avoid this iatrogenic complication, particularly in these high-risk patients.

Prophylactic pancreatic stenting and pharmacological measures have been used to reduce the incidence and severity of PEP. In 2004, a meta-analysis of five randomised controlled trials (RCTs) involving 481 patients demonstrated that patients without prophylactic pancreatic stent (PPS) had a threefold higher odds of developing pancreatitis compared with the stent group $(15.5 \%$ vs $5.8 \%$; OR 3.2 , number need to treat (NNT) 10). ${ }^{5}$ A subsequent meta-analysis of eight RCTs (656 patients) and 10 non-randomised trials (4904 patients) showed similar results. ${ }^{6}$

A meta-analysis of four RCTs $(7678$ patients) showed that patients who received intrarectal non-steroidal antiinflammatory drugs (NSAIDs) in the periprocedural period were $64 \%$ less likely to develop pancreatitis and 90\% less likely to develop moderate to severe pancreatitis $(\mathrm{NNT}=15){ }^{7}$ Recently, a multi-centre RCT of 605 patients showed significant benefit in high-risk cases. ${ }^{8}$

In 2005 , a postal survey returned by 49 expert North American biliary endoscopists showed that 96\% used PPS in selected high-risk cases. ${ }^{9}$ 
In June 2009, a survey completed by 141 participants attending a European therapeutic endoscopy course held in Belgium demonstrated that $78.7 \%$ of respondents inserted PPS. ${ }^{10}$ Statistical analysis showed that measurement of incidence of PEP $(p=0.005)$ and an annual hospital ERCP volume of more than 500 ERCPs $(p=0.030)$ were significantly associated with prophylactic pancreatic stenting. ${ }^{10}$

In June 2010, European Society of Gastrointestinal Endoscopy (ESGE) guidelines were released advising on indications for PPS insertion, stent characteristics, follow-up timing and methods as well as making recommendations on pharmacoprophylaxis and routine post-ERCP amylase measurements in proposed day case procedures. ${ }^{11}$

Our main study aim was to capture current practises of UK biliary endoscopists in the prevention of PEP in the light of these guidelines.

Furthermore, we aimed to ascertain whether any additional operator factors were associated with the decision to introduce PEP prophylaxis measures.

\section{METHODS}

\section{Participant selection}

The biliary endoscopists were identified by contacting every UK Hospital's Endoscopy department in all 10 English Service Health Authorities, Northern Ireland, Scotland and Wales to elicit whether and by whom ERCP was being performed. In all, 373 biliary endoscopists (consultant gastroenterologists, gastroenterology surgeons and radiologists) working at 171 different UK hospitals were identified. The participants' email addresses were obtained from the British Society of Gastroenterology directory, and if not members were found using the National Health Service (NHS) mail search function, the relevant institution website or by contacting the participants' institution IT department/secretarial support team.

\section{Study design and administration}

A 15-item online questionnaire (see online supplementary appendix A) was developed based on the current ESGE guidelines and emailed to the study participants between 30 May 2012 and 14 June 2012. All relevant studies and guidelines referred to in the introduction had been published at this time. All study participants were emailed the identical web link to protect anonymity. No financial or other incentives were offered for completion of the survey. A reminder email was sent to non-responders between 2 July 2012 and 9 July 2012.

\section{Statistical analysis}

A linear stepwise multiple regression analysis was performed to ascertain factors associated with PPS use. $\mathrm{p}$ Values of $<0.05$ were considered statistically significant. The remainder of the survey findings are demonstrated using descriptive statistics.

\section{RESULTS}

\section{Respondent demographics}

In all, 222 of the 373 UK based biliary endoscopists completed the survey (59.5\%). The majority of survey respondents had been performing ERCP for more than 10 years $(n=182 ; 82.4 \%)$. Most respondents had an annual procedure volume of 75-150 ERCPs. The respondents' full demographics subgrouped by PPS use and NSAID use are displayed in table 1.

The number of PPS and NSAID users is displayed as a percentage of the total respondents for each corresponding subdivision.

\section{PPS use}

Of the 219 survey respondents, who stated whether they used PPS or not, 115 (52.5\%) inserted PPS, while $104(47.5 \%)$ never considered inserting them.

In the PPS user group, the individuals stated they always considered placing PPS for the following risk factors (figure 1): pancreatic sphincterotomy (48.9\%), suspected sphincter of Oddi dysfunction (46.5\%), pancreatic duct instrumentation (35.9\%), previous PEP (25.2\%), precut sphincterotomy (8.5\%) and pancreatic duct injection (7.8\%).

The majority of PPS users never inserted pancreatic stents for the following PEP risk factors: trainee involvement in case (58.9\%), patient age less than 60 (58.8\%), female gender $(56.7 \%)$ and balloon dilatation of the biliary sphincter $(56.2 \%)$.

\section{Factors associated with PPS use}

We performed a linear stepwise multiple regression analysis to investigate whether years of ERCP experience, annual personal ERCP volume, Service Health Authority, prophylactic pharmacotherapy use (NSAIDs, antibiotics, intravenous fluids, octreotide) and routine day case post-ERCP amylase measurement were associated with PPS insertion (table 2). Only peri-procedural NSAID use was associated with prophylactic pancreatic stenting at a statistically significant level $(\mathrm{p}<0.001)$.

\section{Stent characteristics}

Of PPS users, 114 respondents stated the type of stent they used (figure 2). In all, 38 (33.3\%) used singleflanged straight stents exclusively. A further $30(26.3 \%)$ employed unflanged pigtail stents, while 21 (18.4\%) used single-flanged pigtail stents. A total of $6(5.3 \%)$ endoscopists used straight unflanged stents.

Of 113 biliary endoscopists who indicated the diameter of their PPS (figure 3), the majority $(n=80$, $70.8 \%$ ) used $5 \mathrm{~F}$ stents exclusively.

There was a wide variation in the length of the pancreatic stents used among the 105 respondents to this question (table 3).

\section{Stent clearance follow-up methods and timing}

In PPS users, the majority $(\mathrm{n}=79 ; 71.8 \%)$ performed a single abdominal radiograph to ensure spontaneous 
Table 1 Overview of survey respondents' demographics (subgrouped by PPS and NSAID use)

\begin{tabular}{|c|c|c|c|}
\hline & All respondents & PPS users & NSAID users \\
\hline Years of ERCP experience & $n=221$ & $n=114$ & $n=71$ \\
\hline $0-5$ & $6(2.7 \%)$ & $4 / 6(66.7 \%)$ & $3 / 6(50.0 \%)$ \\
\hline $6-10$ & $33(14.9 \%)$ & $20 / 33(60.6 \%)$ & 13/33 (39.4\%) \\
\hline$>10$ & $182(82.4 \%)$ & $90 / 182(49.5 \%)$ & $55 / 182(30.2 \%)$ \\
\hline Annual ERCP volume & $n=221$ & $n=115$ & $\mathrm{n}=71$ \\
\hline$<75$ & $13(5.9 \%)$ & $4 / 13(30.7 \%)$ & $3 / 13(23.1 \%)$ \\
\hline $75-150$ & $130(58.8 \%)$ & $71 / 130(54.6 \%)$ & $47 / 130(36.1 \%)$ \\
\hline $150-300$ & $75(33.9 \%)$ & $38 / 75(50.6 \%)$ & $20 / 75(26.6 \%)$ \\
\hline$>300$ & $3(1.4 \%)$ & $2 / 3(66.6 \%)$ & $1 / 3(33.3 \%)$ \\
\hline Service Health Authority & $n=221$ & $n=115$ & $\mathrm{n}=71$ \\
\hline East of England & $16(7.2 \%)$ & $10 / 16(62.5 \%)$ & $5 / 16(31.3 \%)$ \\
\hline East Midlands & $15(6.8 \%)$ & $9 / 15(60.0 \%)$ & $6 / 15(40.0 \%)$ \\
\hline London & $28(12.7 \%)$ & $17 / 28(60.7 \%)$ & $8 / 28(28.5 \%)$ \\
\hline North East & $12(5.4 \%)$ & $7 / 12(58.3 \%)$ & $2 / 12(2.8 \%)$ \\
\hline North West & $23(10.4 \%)$ & $11 / 23(47.8 \%)$ & $11 / 23(47.8 \%)$ \\
\hline South Central & $18(8.1 \%)$ & $8 / 18(44.4 \%)$ & $11 / 18(61.1 \%)$ \\
\hline South East Coast & $11(5.0 \%)$ & $3 / 11(27.2 \%)$ & $2 / 11(18.2 \%)$ \\
\hline South West & $29(13.1 \%)$ & $11 / 29(37.9 \%)$ & $8 / 29(27.5 \%)$ \\
\hline West Midlands & $16(7.2 \%)$ & $12 / 16(75.0 \%)$ & $4 / 16(25.0 \%)$ \\
\hline Yorkshire and the Humber & $13(5.9 \%)$ & $6 / 13(46.2 \%)$ & $3 / 13(23.1 \%)$ \\
\hline Northern Ireland & $10(4.5 \%)$ & $6 / 10(60.0 \%)$ & $6 / 10(60.0 \%)$ \\
\hline Scotland & $16(7.2 \%)$ & $5 / 16(31.3 \%)$ & $4 / 16(25 \%)$ \\
\hline Wales & $14(6.3 \%)$ & $10 / 14(71.4 \%)$ & $3 / 14(21.4 \%)$ \\
\hline
\end{tabular}

pancreatic stent passage. In all, $6(5.4 \%)$ respondents performed serial abdominal radiographs to check for stent passage, 17 (15.5\%) respondents arranged for endoscopy to remove PPS without prior abdominal x-ray while $8(7.3 \%)$ respondents did not follow-up stent clearance at all (figure 4).

Overall, 84 biliary endoscopists indicated the number of days until obtaining their final abdominal $\mathrm{x}$-ray prior to attempting stent retrieval (figure 5). Most respondents $(\mathrm{n}=37,44.0 \%)$ performed their last abdominal radiograph 11-14 days post stent insertion. After this time, endoscopic retrieval was undertaken where the stent was retained.

\section{Reasons for non-PPS use}

Of the 104 respondents who did not use PPS, 92 stated their reasons for not using them. Several respondents chose multiple reasons. Overall, 59 (64.1\%) respondents were not convinced of the protective effect of PEP in preventing PEP, whereas $38(41.3 \%)$ felt that they had insufficient experience in placing pancreatic stents, $23(25 \%)$ were concerned about the increased risk of PEP in cases of failed prophylactic stent insertion and $12(13 \%)$ respondents did not have pancreatic stents available to them in their institution. Thirteen gave other reasons with the most common one (nine respondents) being that PPS

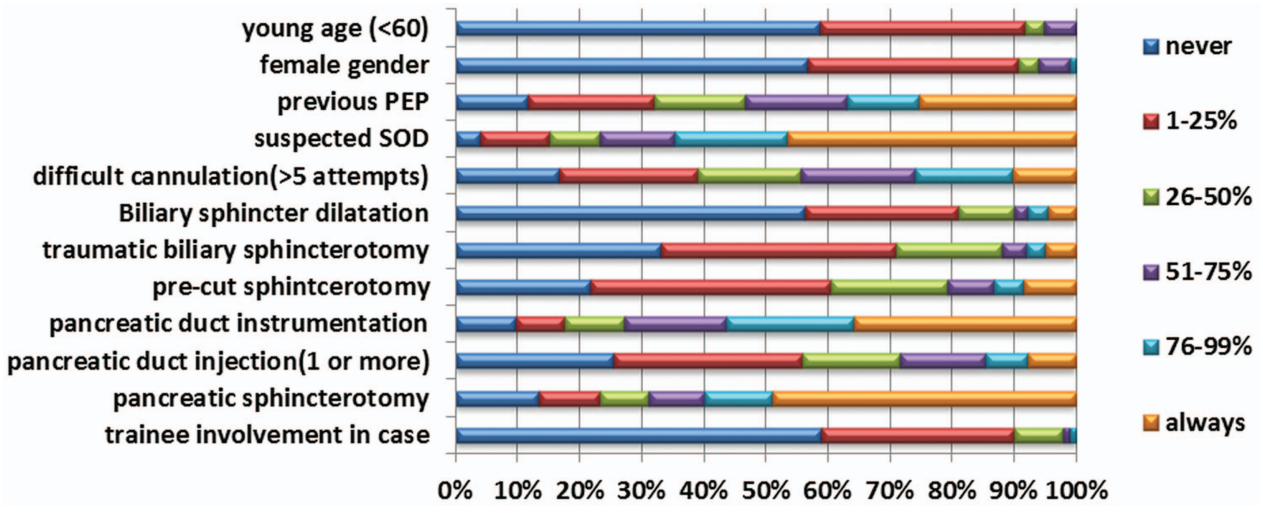

Figure 1 Percentage of endoscopic retrograde cholangiopancreatographies (ERCPs) with prophylactic pancreatic stent placement by post-ERCP pancreatitis (PEP) risk factor. The total number of responses for each PEP risk factor ranged from 89 to 108. 
Table 2 Multiple logistic regression analysis of factors possibly associated with prophylactic pancreatic stents use

\begin{tabular}{lr}
\hline Factor & $\mathrm{p}$ Value \\
\hline Years of ERCP experience & 0.404 \\
Annual personal ERCP volume & 0.512 \\
Service Health Authority & 0.725 \\
NSAID use & $<0.001$ \\
Octreotide use & 0.079 \\
Antibiotic use & 0.856 \\
Intravenous fluid use & 0.647 \\
Routine postprocedure amylase measurement & 0.948 \\
\hline ERCP, endoscopic retrograde cholangiopancreatography; & \\
NSAID, non-steroidal anti-inflammatory drug. &
\end{tabular}

insertion was unlikely to significantly improve their PEP rate as it was already very low.

\section{Pharmacotherapy use and post-ERCP amylase measurement}

In all, 72 respondents (34.6\%) used NSAIDs in the prophylaxis of PEP, whereas 136 (65.4\%) did not use them. Rapid intravenous fluids were employed by 25 respondents (13.2\%). Three respondents used octreotide. Antibiotics for the prophylaxis of PEP were routinely prescribed by 41 respondents (20.6\%). Table 4 displays the survey respondents' use of pharmacoprophylaxis and routine post-ERCP amylase measurement subgrouped by PPS use.

\section{DISCUSSION}

This study represents the first survey to date of the practice of UK hepatobiliary endoscopists in using strategies to prevent PEP.

Surprisingly, only about a half of UK biliary endoscopists considered prophylactic pancreatic stenting and only a third used NSAIDs despite the introduction of the ESGE guidelines and Grade A recommendations existing for both.
By contrast, a similar North American survey ${ }^{9}$ found that $96 \%$ used PPS and an EU survey ${ }^{10}$ found that $78.7 \%$ of survey respondents inserted them.

Our study had more respondents compared with the other two studies (222, 141 and 49, respectively). This difference may account for some of the variation and it may therefore be the case that our figure of approximately $50 \%$ stent users is more representative of the true clinical practice.

It appeared that the biliary endoscopists who used PPS underused them for several high-risk interventions such as Sphincter of Oddi Dysfunction (SOD) and pancreatic endotherapy.

While the majority of respondents (70.0\%) employed 5F stents exclusively as recommended by the ESGE guidelines, there was a wide variation in the stent length and design being used. This is perhaps understandable because although the ESGE guidelines currently advise the use of short $5 \mathrm{~F}$ pancreatic stents, ${ }^{11}$ no recommendation on the exact ideal stent length or design is made. This may be because most of the characteristics of the 'ideal' PPS are currently unknown. ${ }^{12}$

Most PPS users (77.2\%) performed an abdominal $\mathrm{x}$-ray prior to attempting stent retrieval, while a significant number proceeded straight to endoscopy $(15.5 \%)$. In both groups the timing varied greatly. The ideal time for PPS to remain in situ is currently unknown. ${ }^{13}$ It is unclear whether the protective effect of prophylactic pancreatic stenting is reversed if the pancreatic stent is removed too early although it is likely that beneficial effects occur early after ERCP. Sherman et $a l^{14}$ found that when PPS were removed immediately following precut sphincterotomy, the risk of PEP was significantly increased compared with stents that remained in situ for $7-10$ days $(2.2 \%$ vs $21.3 \% ; \mathrm{p}=0.004)$. Two other studies showed that early stent passage at 24 and $72 \mathrm{~h}$ respectively was not a significant risk factor for the development of PEP suggesting that physical removal of the stent may be a risk factor for provoking pancreatitis. ${ }^{15} 16$ Moffatt

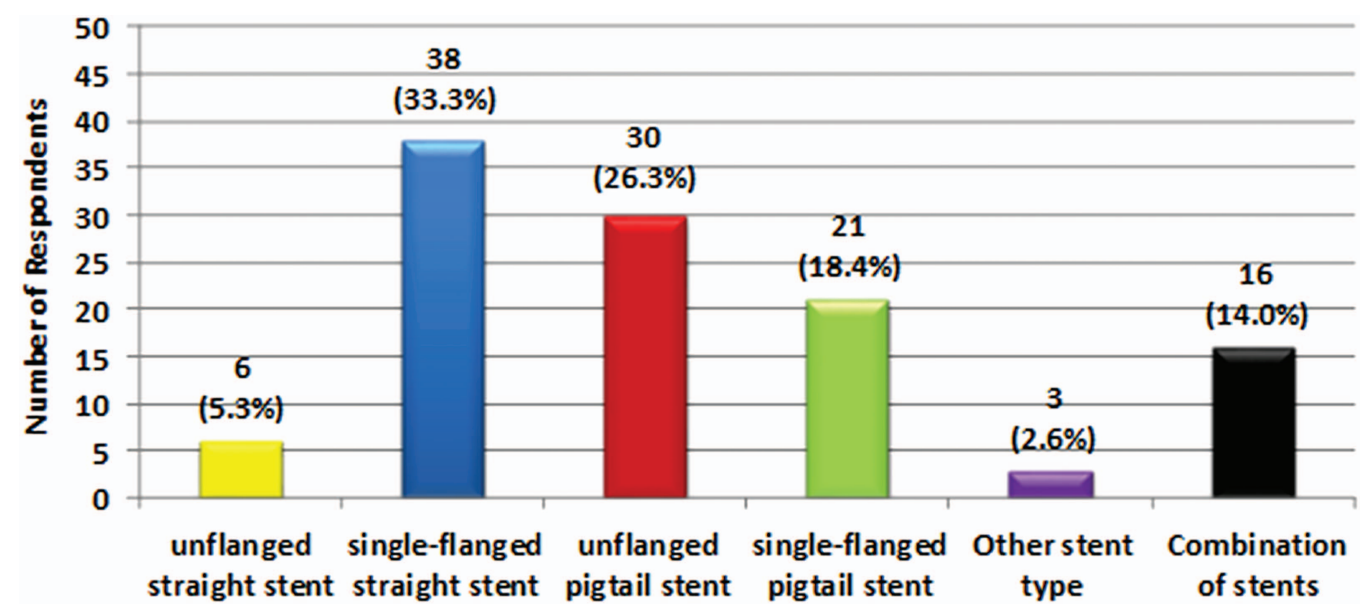

Figure 2 Survey respondents' stent type used. 


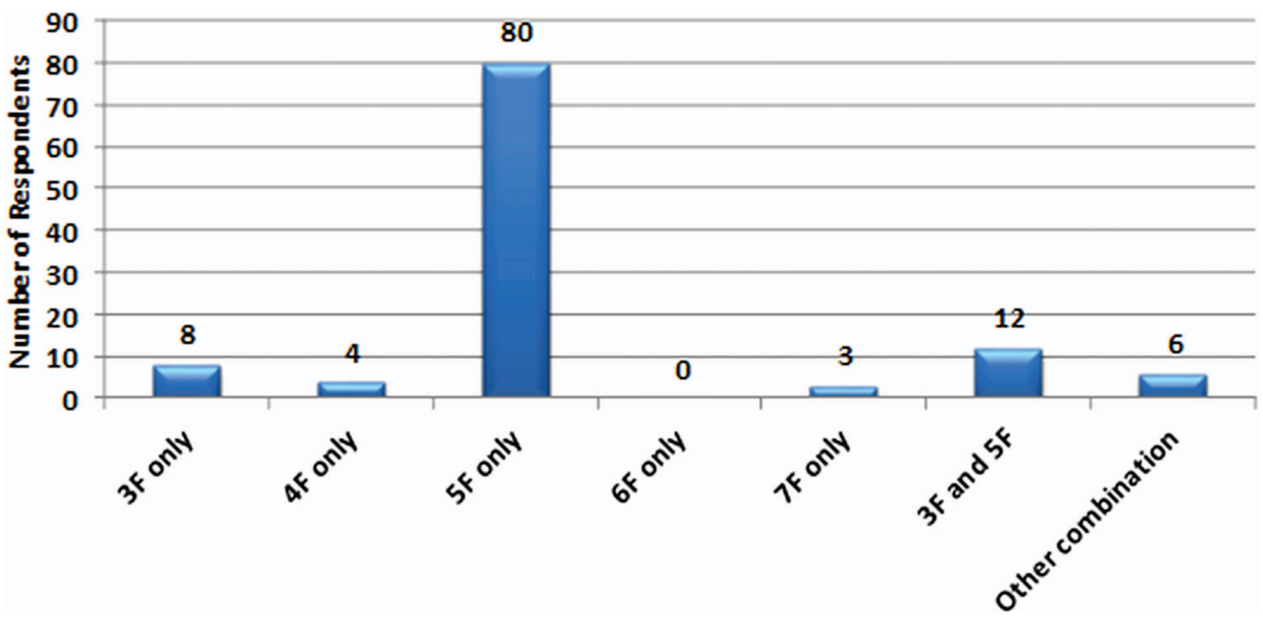

Figure 3 Survey respondents' stent diameter used.

et $a l^{17}$ found in their retrospective study of 230 patients undergoing endoscopic PPS removal that 3\% developed acute pancreatitis.

Pancreatic stents that remain in situ for more than 2 weeks have been shown to increase the risk of PEP more than five times compared with patients with spontaneous stent elimination at 2 weeks or less ${ }^{15}$ while it is also known that they confer an increased risk of stent-induced pancreatic duct changes and subsequently chronic pancreatitis. ${ }^{18} 19$

ESGE guidelines currently recommend obtaining follow-up imaging 5-10 days post stent insertion with prompt retrieval if they are still found to be in situ. $^{11}$

Our study showed a correlation between pancreatic stent use and the use of NSAIDs at a statistically significant level $(p<0.001)$. This may be related to a higher case load of patients at increased risk of PEP among these biliary endoscopists or simply their increased awareness of methods of PEP prevention.

Current ESGE guidelines recommend the use of $100 \mathrm{mg}$ diclofenac or indomethacin via the intrarectal route immediately before or after ERCP to reduce the incidence of PEP $^{11}$ Approximately a third of our respondents used NSAIDs. It is noteworthy that in the survey by Dumonceau et al, ${ }^{10}$ only $16.3 \%$ of

Table 3 Survey respondents stent length used

\begin{tabular}{lc}
\hline Stent length & Number of respondents $(\%) \mathrm{n}=105$ \\
\hline $3 \mathrm{~cm}$ only & $25(23.8 \%)$ \\
$4 \mathrm{~cm}$ only & $16(15.2 \%)$ \\
$5 \mathrm{~cm}$ only & $20(19.0 \%)$ \\
$6 \mathrm{~cm}$ only & $5(4.8 \%)$ \\
$7 \mathrm{~cm}$ only & $1(1.0 \%)$ \\
3 and $4 \mathrm{~cm}$ & $6(5.7 \%)$ \\
3 and $5 \mathrm{~cm}$ & $13(12.4 \%)$ \\
4 and $5 \mathrm{~cm}$ & $4(3.8 \%)$ \\
5 and $7 \mathrm{~cm}$ & $5(4.8 \%)$ \\
Other combinations & $10(9.5 \%)$ \\
\hline
\end{tabular}

respondents used NSAIDs. At the time this was attributed to insufficient scientific evidence supporting their use. The higher number of NSAID users in our survey might be explained by the results of subsequent RCT. This RCT of 602 patients undergoing ERCP showed that even in patients at increased risk of developing PEP, intrarectal indomethacin was effective in reducing its incidence. ${ }^{8}$

A prospective Australian study of 263 ERCPs showed that a serum amylase level of less than 1.5 times the upper limit of normal measured $4 \mathrm{~h}$ post-ERCP had a negative predictive value of $100 \%$ in excluding PEP. $^{20}$ The ESGE guidelines recommend measuring serum amylase levels post-ERCP in day case patients to facilitate safe discharge. ${ }^{11}$ Interestingly, only $6 \%$ of our respondents performed this practice in their day case patients prior to discharge. A potential reason may be that it can be impractical to process blood results in sufficient time to make this practical especially considering current bed pressures in the NHS.

The two main reasons cited among our survey respondents for not inserting PPS in high-risk patients were lack of conviction in their benefits and insufficient experience in inserting them. This is interesting given published guidelines existing with high grade evidential support for the interventions.

Another reason cited for non-insertion was the perception of a low incidence of PEP in non-PPS/NSAID users. Unfortunately, data are lacking for postprocedural complications such as PEP otherwise it might be of interest to try and correlate interventions with real practice incidence of these complications or hospitalisation post-ERCP. Prophylactic pancreatic stenting has been shown to reduce the incidence of PEP and reduce its severity when it occurs. ${ }^{21}$ It could therefore be the case that even endoscopists with a low PEP rate may benefit from inserting PPS.

Our study may be potentially susceptible to nonresponder and recall bias. Non-respondents may have had less interest in methods of PEP prevention. It is conceivable that the respondents selected gave what 
Table 4 Pharmacoprophylaxis use and post-ERCP amylase measurement (subgrouped by PPS vs non-PPS use)

\begin{tabular}{|c|c|c|c|c|c|c|}
\hline \multirow[b]{2}{*}{ Pharmacoprophylaxis use } & \multicolumn{2}{|l|}{ Overall } & \multicolumn{2}{|l|}{ PPS users } & \multicolumn{2}{|c|}{ Non-PPS users } \\
\hline & Yes & No & Yes & No & Yes & No \\
\hline NSAID & $72(34.2 \%)$ & $136(65.4 \%)$ & $53(47.3 \%)$ & $59(52.7 \%)$ & $18(19.1 \%)$ & $76(80.9 \%)$ \\
\hline Antibiotics & $41(20.6 \%)$ & $158(79.4 \%)$ & $17(17.2 \%)$ & $82(82.8 \%)$ & $24(24.2 \%)$ & $75(75.8 \%)$ \\
\hline Intravenous fluids & $25(13.2 \%)$ & $165(86.8 \%)$ & $16(16.2 \%)$ & $83(83.8 \%)$ & $9(10.0 \%)$ & $81(90.0 \%)$ \\
\hline Octreotide & $3(1.6 \%)$ & $185(98.4 \%)$ & $0(0 \%)$ & $97(100 \%)$ & $3(3.3 \%)$ & $87(96.7 \%)$ \\
\hline Post-ERCP amylase measurement & $13(6.0 \%)$ & $205(94.0 \%)$ & $6(5.3 \%)$ & $108(94.7 \%)$ & $7(6.9 \%)$ & $94(93.1 \%)$ \\
\hline
\end{tabular}

The overall number of respondents included respondents who did not declare whether they used PPS or not.

ERCP, endoscopic retrograde cholangiopancreatography; NSAID, non-steroidal anti-inflammatory drug; PPS, prophylactic pancreatic stent.

they thought to be the 'correct' answer rather than what they do in their own practice. On balance, our results represent the best-case scenario in terms of PPS insertion and pharmacoprophylaxis use. Furthermore, although all of the selected respondents were practising ERCP at a consultant level, it is unclear from our survey whether they received specific training in inserting pancreatic stents considering that over $40 \%$ of respondents cited insufficient experience in pancreatic stenting for non-use. It may beneficial for future trainees to attend mandatory Joint Advisory Group on GI Endoscopy (JAG) accredited ERCP courses where the indications of stents insertion as well as technical aspects of insertion could be taught and demonstrated. It could also be argued that due to the critical importance of using NSAIDs and/or PPS in preventing PEP that this could be added as Global Rating Scale (GRS) auditable field such as the use of antibiotics for incomplete drainage.

Although both NSAIDs ${ }^{22}$ and PPS $^{23}$ have been confirmed to be independently effective in recent meta-analyses, the most effective overall strategy is currently unknown. ESGE guidelines recommend the routine use of intrarectal NSAIDs in low-risk cases and PPS for high-risk cases. ${ }^{11}$ A recent meta-analysis of 29 studies (22 of pancreatic duct (PD) stents and seven of

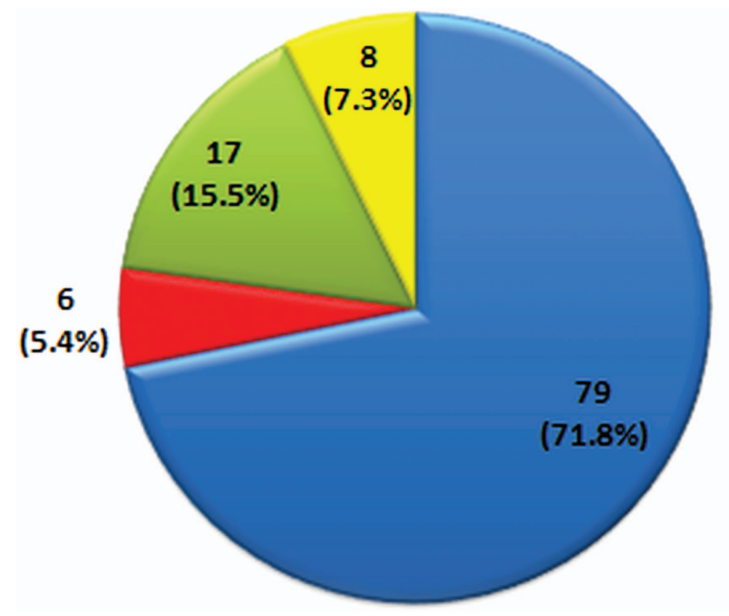

Single Abdominal X-Ray

Serial Abdominal X-Rays

Endoscopy to remove stent without prior radiograph

Not at all

Figure 4 Survey respondents' pancreatic stent follow-up method.

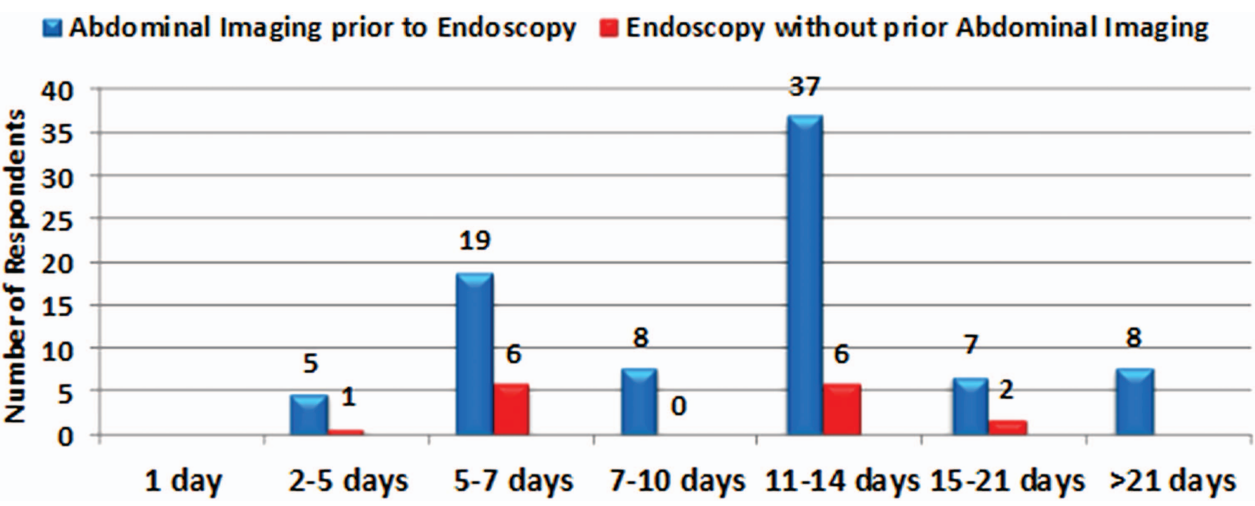

Figure 5 Number of days to obtaining prophylactic pancreatic stents follow-up imaging/attempting stent retrieval. 
NSAIDs) showed that intrarectal NSAIDs alone were superior to PD stents alone in preventing PEP. $^{24}$ However, as the authors acknowledge, these findings are limited by the small number of studies assessed and the indirect nature of the comparison. ${ }^{24}$ Furthermore, a post hoc economic analysis of a single RCT showed that intrarectal NSAIDs were more cost-effective than PPS. ${ }^{25}$ Several large scale RCTs directly comparing NSAIDs

\section{What is already known on this topic}

- Postendoscopic retrograde cholangiopancreatography (post-ERCP) pancreatitis (PEP) is the most common and serious complication of ERCP.

- Both prophylactic pancreatic stenting and periprocedural non-steroidal anti-inflammatory drug use have been shown to significantly reduce the incidence of PEP and their use is recommended by the European Society of Gastrointestinal Endoscopy guidelines.

\section{What this study adds}

- This represents the first UK wide survey of hepatobiliary endoscopist practices in reducing postendoscopic retrograde cholangiopancreatography (post-ERCP) pancreatitis (PEP).

- Approximately half of UK endoscopists performing ERCP use prophylactic pancreatic stents, while a third use non-steroidal anti-inflammatory drugs (NSAIDs) as PEP prophylaxis.

- Despite strong evidence, the main reason cited for not using pancreatic stenting is a personal belief of their non-effectiveness in preventing PEP.

- Prophylactic pancreatic stent use is associated with peri-procedural NSAID use at a statistically significant level, while years of ERCP experience, annual personal ERCP volume, UK region and routine post-ERCP amylase measurement are not.

How might it impact on clinical practice in the foreseeable future

- There is evidence available that would facilitate safer endoscopic practice in preventing postendoscopic retrograde cholangiopancreatography pancreatitis. Awareness of these data is significantly lower in the UK than in Europe and the USA. It is possible that European Society of Gastrointestinal Endoscopy guidelines are not used as terms of reference by UK endoscopists and that British Society of Gastroenterology guidelines might improve compliance. versus PPS versus a combination of both are essential in clarifying the optimal overall strategy to prevent PEP.

In summary, prophylactic pancreatic stenting and NSAID use although shown to be effective in reducing the incidence of PEP were underused among UK biliary endoscopists. Guidelines and evidence already exists for these safer practice measures and these data are important to stimulate debate and increase awareness among practicing biliary endoscopists in the UK.

Acknowledgements We are indebted to our survey respondents for kindly completing our survey.

Contributors MSH, AJP and RP were involved in the concept and design of the survey; MSH collected, assembled, analysed and interpreted the data and wrote the manuscript; ADD performed the multiple regression analysis; AJP and RP supervised the analysis, interpreted the data, critically reviewed and edited the manuscript. All authors have approved the final version of the article, including the authorship list. MSH accepts responsibility for the integrity of the work as a whole from inception to the published article.

\section{Competing interests None.}

Provenance and peer review Not commissioned; externally peer reviewed.

Open Access This is an Open Access article distributed in accordance with the Creative Commons Attribution Non Commercial (CC BY-NC 3.0) license, which permits others to distribute, remix, adapt, build upon this work non-commercially, and license their derivative works on different terms, provided the original work is properly cited and the use is noncommercial. See: http://creativecommons.org/licenses/by-nc/3.0/

\section{REFERENCES}

1 Andriulli A, Loperfido S, Napolitano G, et al. Incidence rates of post-ERCP complications: a systematic survey of prospective studies. Am J Gastroenterol 2007;(102):1781-8.

2 Masci E, Mariani A, Curioni S, et al. Risk factors for pancreatitis following endoscopic retrograde cholangiopancreatography: a meta-analysis. Endoscopy 2003;35:830-4.

3 Cheng CL, Sherman S, Watkins JL, et al. Risk factors for post-ERCP pancreatitis: a prospective multicenter study. Am J Gastroenterol 2006;101:139-47.

4 Freeman ML, DiSario JA, Nelson DB, et al. Risk factors for post-ERCP pancreatitis: a prospective, multicenter study. Gastrointest Endosc 2001;54:425-34.

5 Singh P, Das A, Isenberg G, et al. Does prophylactic pancreatic stent placement reduce the risk of post-ERCP acute pancreatitis? A meta-analysis of controlled trials. Gastrointest Endosc 2004;60:544-50.

6 Choudhary A, Bechtold ML, Arif M, et al. Pancreatic stents for prophylaxis against post-ERCP pancreatitis: a meta-analysis and systematic review. Gastrointest Endosc 2011;73:275-82.

7 Elmunzer BJ, Waljee AK, Elta GH, et al. A meta-analysis of NSAIDs in the prevention of post-ERCP pancreatitis. Gut 2008;57:1262-7.

8 Elmunzer BJ, Scheiman JM, Lehman GA, et al. A randomized trial of rectal indomethacin to prevent post-ERCP pancreatitis. N Engl J Med 2012;366:1414-22.

9 Brackbill S, Young S, Schoenfeld P, et al. A survey of physician practices on prophylactic pancreatic stents. Gastrointest Endosc 2006;64:45-52.

10 Dumonceau JM, Rigaux J, Kahaleh M, et al. Prophylaxis of post-ERCP pancreatitis: a practice survey. Gastrointest Endosc 2010;71:934-9, 939.e1-2. 
11 Dumonceau JM, Andrulli A, Deviere J, et al. European Society of Gastrointestinal Endoscopy (ESGE) Guideline: prophylaxis of post-ERCP pancreatitis. Endoscopy 2010;42:503-15.

12 Elta G. Prophylactic Pancreatic Duct Stents. Gastroenterol Hepatol (NY) 2008;4:251-3.

13 Donnellan F, Byrne MF. Prevention of post-ERCP pancreatitis. Gastroenterol Res Pract 2012;2012:796751.

14 Sherman S, Earle D, Bucksot L, et al. Does leaving a main pancreatic duct stent in place reduce the incidence of precut biliary sphincterotomy (ES)-induced pancreatitis? A final analysis of a randomized prospective study. Gastrointestinal Endosc 1996:43:A413.

15 Chahal P, Tarnasky P, Petersen B, et al. Short 5Fr vs long 3Fr pancreatic stents in patients at high risk for post- endoscopic cholangiopancreatography pancreatitis. Clin Gastroenterol Hepatol 2009;7:834-9.

16 Moffatt DC, Pradermchai K, Avuka H, et al. Moderate and severe post-ERCP pancreatitis despite prophylactic pancreatic stent placement. The effect of early prophylactic pancreatic stent dislodgement. Can J Gastroenterol 2011;25:215-19.

17 Moffatt DC, Coté GA, Fogel EL, et al. Acute pancreatitis after removal of retained prophylactic pancreatic stents. Gastrointest Endosc 2011;73:980-6.

18 Sherman S, Hawes RH, Savides TJ, et al. Stent-induced pancreatic ductal and parenchymal changes: correlation of endoscopic ultrasound with ERCP. Gastrointest Endosc 1996;44:276-82.
19 Smith MT, Sherman S, Ikenberry SO, et al. Alterations in pancreatic ductal morphology following polyethylene pancreatic stent therapy. Gastrointest Endosc 1996;44:268-75.

20 Thomas PR, Sengupta S. Prediction of pancreatitis following endoscopic retrograde cholangiopancreatography by the 4-h post procedure amylase level. J Gastroenterol Hepatol 2001;16:923-6.

21 Freeman ML. Pancreatic stents for prevention of post-endoscopic retrograde cholangiopancreatography pancreatitis. Clin Gastroenterol Hepatol 2007;5:1354-65.

22 Ding X, Chen M, Huang S, et al. Nonsteroidal anti-inflammatory drugs for prevention of post-ERCP pancreatitis: a meta-analysis. Gastrointest Endosc 2012;76:1152-9.

23 Mazaki T, Mado K, Masuda H, et al. Prophylactic pancreatic stent placement and post-ERCP pancreatitis: an updated meta-analysis. J Gastroenterol 2013. [Epub ahead of print].

24 Akbar A, Abu Dayyeh BK, Baron TH, et al. Rectal nonsteroidal anti-inflammatory drugs are superior to pancreatic duct stents in preventing pancreatitis after endoscopic retrograde cholangiopancreatography: a network meta-analysis. Clin Gastroenterol Hepatol 2013;11:778-83.

25 Elmunzer BJ, Higgins PD, Saini SD, et al. United States Cooperative for Outcomes Research in Endoscopy. Does rectal indomethacin eliminate the need for prophylactic pancreatic stent placement in patients undergoing high-risk ERCP? Post hoc efficacy and cost-benefit analyses using prospective clinical trial data. Am J Gastroenterol 2013;108:410-15. 